\title{
Differentiated Toll Optimization on Goods Vehicles Based on Prediction of Demand for Large-Scale Network
}

\author{
Hua Zhao, ${ }^{1,2}$ Zifeng Peng, ${ }^{3}$ Zhihong Li $\mathbb{D},{ }^{4}$ and Weiting Yao ${ }^{4}$ \\ ${ }^{1}$ Jiangxi Transportation Institute Co., Ltd, Nanchang 330200, China \\ ${ }^{2}$ School of Civil Engineering and Architecture, Nanchang University, Nanchang 330031, China \\ ${ }^{3}$ Jiangxi Transportation Engineering Group Co., Ltd, Nanchang 330000, China \\ ${ }^{4}$ School of Civil and Transportation Engineering, Beijing University of Civil Engineering and Architecture, Beijing 100044, China \\ Correspondence should be addressed to Zhihong Li; lizhihong@bucea.edu.cn
}

Received 18 December 2021; Revised 4 January 2022; Accepted 13 January 2022; Published 25 January 2022

Academic Editor: Zhenzhou Yuan

Copyright (C) 2022 Hua Zhao et al. This is an open access article distributed under the Creative Commons Attribution License, which permits unrestricted use, distribution, and reproduction in any medium, provided the original work is properly cited.

\begin{abstract}
The area rate of the toll road network is designed to influence the regional road network traffic flow configuration and an important factor of goods vehicle path selection, transportation, and other related departments in formulating the related standard. The toll rate is usually combined with the local passenger and cargo loading conditions. Adjusting and optimizing the charge policy, optimization of processes and methods is still facing many difficulties. In this paper, the model parameters and toll status of various goods vehicles are considered, and an optimization algorithm of toll rates for different vehicles in a large-scale road network is proposed. By constructing a traffic demand prediction model based on multiple truck classification, this paper analyzes the distribution status of network trucks and the final charging under the influence of different rates. At the bottom of the algorithm is an analytical model composed of nonlinear equations whose dimensions scale linearly with the scale of the road network. The scale of the road network is independent of the path set and link attribute. The model is verified and the parameters are calibrated by a small network. Finally, the Road network is selected for empirical analysis in Xinjiang Autonomous Region. A case study shows that the analytical structure information provided by the analytic network model enables the algorithm to quickly identify high quality solutions, and the algorithm has better simulation accuracy and premium rate design advantages.
\end{abstract}

\section{Instruction}

Freeway is an important infrastructure of national transportation, which has significant advantages such as high speed and comfortable driving. The national freeway network has been basically improved. The funds for freeway construction are usually composed of three parts: government funds, bank loans, and private funds. Generally, domestic freeway relies on toll collection to recover costs, repay loans, and manage operation management. At the same time, charging tolls also helps to regulate road traffic and improve traffic efficiency. However, in many years of development, the freeway faces many problems, such as serious congestion, unbalanced traffic flow distribution [1], high freight cost, Increased vehicle emissions [2], the uncertainty of toll collection, and so on [3]. In 2016, the Ministry of transport of China put forward the concept of differentiated freeway charging. This policy provides ideas for solving the problems faced by freeway freight transportation.

In May 2019, the State Council of China explicitly requested the abolition of provincial toll stations of freeways and actively guided all localities to try differentiated toll collection methods from multiple angles, especially in provinces with large differences in freight traffic flow characteristics, differentiated according to road sections, time periods, driving directions, specific entrances, and exits and other factors, and gradually fully implemented differentiated toll collection of freeways. This can improve the traffic efficiency of the freeway network, promote the cost reduction and efficiency increase of the logistics industry, and promote the development of the local economy. 
In August 2019, the national development and Reform Commission issued the notice on earnestly doing a good job in the adjustment of goods vehicle toll charging method, which requires to speed up the adjustment of goods vehicle model classification. Under the new vehicle charging system, the charging rate, charging method, and charging fees of freeways in all provinces in China need to be recalculated and adjusted to make it clear that they cannot increase the social and economic burden but also ensure the normal operation of freeways, which puts forward new problems for the highway charging policy. At present, some provinces have carried out pilot work in combination with local characteristics, such as Sichuan, Zhejiang, Henan, Guangxi, and so on. According to the analysis of the existing pilot charging data, in 2017, the burden of freight enterprises and drivers in Shanxi Province was reduced by 1.792 billion yuan, and the freight traffic increased by $37.1 \%$. This shows that differentiated charging is an effective means to regulate freeway traffic flow.

This paper focuses on the freight vehicles in the freeway network of Xinjiang Autonomous Region and optimizes the rate of freight vehicles of different grades. A goods vehicles toll rate optimization model based on demand analysis under a large-scale network is constructed, and multiple schemes are analyzed and compared.

The main contributions of this paper are as follows:

(1) A goods vehicles toll rate optimization model based on demand analysis under a large-scale network is constructed.

(2) Based on the model, multiple schemes are analyzed and compared.

(3) The research results have played a good supporting role in the truck toll rate designated by the government of Xinjiang Autonomous Region. It also provides a reference for the charging methods and rate changes in other regions.

The chapter arrangement of the paper is as follows. The second chapter is the literature review, which analyzes the current research status and existing problems in detail. The third chapter is the current situation and data analysis, relying on the big data of freeway traffic flow in Xinjiang Autonomous Region to analyze the characteristics and rates. The fourth chapter is the modeling part. Based on the modeling analysis of the freeway network in Xinjiang Autonomous Region, the toll rate optimization analysis and dynamic adjustment calculation of 6 types of freight cars are carried out. The fifth chapter is the discussion part. The last part is the conclusion.

\section{Related Research}

In recent years, facing the problem of traffic congestion, many scholars have studied how to reduce highway traffic congestion $[4,5]$. Congestion charging is a mature strategy which has been implemented in Singapore, London, New York, and other places. Some researchers pay attention to the implementation methods and performance evaluation
[6]. Agarwal et al. analyzed the impact of periodic congestion rate adjustment on commuter traffic mode selection in Singapore and the effect of ERP [7, 8]. Martin et al. studied the traffic efficiency of High Occupancy Vehicle (HOV) Lane [9]. Although congestion charge has been applied for a long time, there are still some problems.

There are relatively few researches on differentiated charging at home and abroad, mainly focusing on the analysis of differentiated charging by the time period of freight cars [10], the evaluation of differentiated charging based on traffic demand analysis [11], the establishment of a hybrid model for the optimization of charging scheme [12]. They made a preliminary analysis of differentiated charging from the perspective of operating income and regional economic development and made a comparative analysis and evaluation before and after the change of charging policy based on the traffic demand model and from time-saving benefits, traffic status, and other indicators. Finally, the corresponding optimal charging scheme is proposed.

In the study of Freeway rate based on the theoretical level, Yang and Zhao studied the changing relationship between traffic volume and charging standard and the factors that should be considered in the formulation of charging standard, established the traffic volume transfer model by vehicle type, and proposed that the freeway rate should meet the three conditions of maximum social benefit, balanced operation revenue, and expenditure and user economic affordability [13]. Li introduced the hotel in a model into the field of traffic demand management and concluded that the difference between the rates of the two toll roads is related to the going distance of the two roads, the driving time and added value of the two roads, and the personal preference of travel [14]. Yao and Wang expounded the decision-making characteristics of the Freeway PPP project, analyzed the impact of the project on Pricing in detail, put forward relevant solutions, and gave the theoretical model of new freeway and project charging rate [15]. Xie et al. considered the system optimization theory and considered the early investment and operation management expenditure of freeway, established a bilevel programming model of fee for expenditure [16]. Taothon et al. analyzed public private partnerships in toll road investments [17]. Zhou and Koppelman et al. modeled Lane-Choice Behavior to optimize pricing strategy for HOT lanes based on regression [18-20]. Steed et al. modeled department time choice for home based nonwork trips [21].

In the study of freeway toll rates based on actual cases, $\mathrm{Fu}$ studied the optimization of freeway toll rates under competitive conditions, and combined it with Xin Yu Fu freeway, giving the specific rate optimization process [22]. Wang et al. evaluated the financial crisis level of highway toll enterprises according to the cash flow analysis and calculated through the rate optimization model. They believe that rate optimization can effectively reduce the risk of the financial crisis caused by cash flow fracture of highway toll enterprises [23, 24]. At present, most of the research is from the perspective of enterprise operation, toll road project management mode, and project investment risk. However, few quantitative works are carried out on public welfare toll road projects. 
Freeway projects in Xinjiang are government loan projects focusing on public welfare services, and the adjustment of rates pays more attention to social response and policy balance. Due to the sparsely populated area and rich mineral resources, Xinjiang has a long average haul distance for highway freight transportation. Therefore, the formulation of the new rate should comply with the characteristics of Xinjiang, fully consider the structural characteristics of the whole Xinjiang road network and the distribution characteristics of goods vehicle travel, and balance the relationship between the old and new rate standards. The recommended scheme is the rate standard that does not increase the overall social burden of goods vehicles and has the smallest fluctuation in toll income of freeways in Xinjiang. Based on the real situation of goods vehicle charging in the Xinjiang freeway network, this paper optimizes the freeway network charging rate in Xinjiang so as to provide a reference for carrying out relevant policy research.

\section{Methodology}

3.1. Road Network Structure. By the end of December 2018, the mileage of toll roads in Xinjiang Uygur Autonomous Region was $10150.69 \mathrm{~km}$, all of which were government loan repayment toll roads, which were operated and managed by the Highway Administration Bureau of Xinjiang Uygur Autonomous Region. Among them, there are $4467.82 \mathrm{ki}-$ lometers of freeways, 338.34 kilometers of first-class, and 5344.53 kilometers of second-class highways, accounting for $44.01 \%$, 3.33\%, and 52.65\%, respectively. There are 78 Main Line toll stations in the region, including 39 freeways, 4 firstclass, and 35 second-class highways, accounting for $50.00 \%$, $5.13 \%$, and $44.87 \%$, respectively. In 2018 , goods vehicle tolls accounted for $77.75 \%$ of freeway tolls, about 6.751 billion yuan.

It shows the details of toll stations in the whole autonomous region in Figure 1. There are 211 toll stations in the whole range, including 141 closed toll stations, 70 open toll stations, and 4 interchange nodes. It shows the road network distribution of Xinjiang freeway and first-class highway in Figure 2.

\subsection{Operation Characteristic Analysis. According to China's} transportation industry standard JT/t489-2019 (Vehicle classification of the toll for highway), the goods vehicles are divided into 6 types. Category 1 goods vehicle refers to a 2axle freight car with a total mass of less than $4500 \mathrm{~kg}$. Category 2 goods vehicle is 2 -axle freight cars with a total mass of not less than $4500 \mathrm{~kg}$. Category 3-6 goods vehicle, respectively, correspond to 3-6 axle trucks, as shown in Table 1.

The classification of the 2019 standard is obviously different from the previous version of China's transportation industry standard. In the previous version, goods vehicles are classified according to the rated load mass $(\mathrm{kg})$ approved by relevant national administrative departments after leaving the factory, as shown in Table 2.
The proportion of various goods vehicle traffic volume, average total vehicle weight, and average haul distance of Xinjiang expressway are shown in Table 3. It can be seen that the goods vehicles of Xinjiang highway in 2018 were mainly heavy load vehicles. According to the statistics, the traffic volume of category 1 6 goods vehicles is 25.89 million, including 17.25 million category 6 goods vehicles, accounting for $66.62 \%$ of the total number of goods vehicles. Followed by class 1 and class 2 goods vehicles, it reached 4.12 million and 2.13 million respectively. Category 1 goods vehicles accounted for $15.91 \%$. Category 3 and category 5 vehicles are the least, with only 0.95 and 0.33 million vehicles per year, accounting for less than $5 \%$ of the total.

The average gross vehicle and cargo weight increased from 2.5 tons of class 1 vehicles to 40.32 tons of class 6 vehicles, with an average of 20.98 tons. The models with long average haul distance are mainly concentrated in category 3 , category 5, and category 6 goods vehicles, which are $68.99 \mathrm{~km}, 75.41 \mathrm{~km}$, and $71.27 \mathrm{~km}$, respectively.

The load distribution of cargo vehicles in the expressway network is shown in Table 4. Among them, the load balance point refers to the no-load and full load balance point of trucks, which is one of the bases for the government to formulate charging standards. As shown in Table 4, the load balance point of category 1 goods vehicles is 4.11 tons, which is slightly less than the requirement of category 1 or lower than 4.5 tons in the standard. It means that if it carries more than 4.11 tons of category 1 , the more it carries, the higher the cost per kilogram. Under the influence of this constraint, the load of category 1 is light, and no vehicle load exceeds 4.11 tons. The load balance point of category 2 is 8.92 tons, where the proportions of light and heavy loads are $62 \%$ and $38 \%$, respectively. The higher the vehicle load, the higher the proportion of heavy load. This is closely related to current freight profit in China.

Compared with the freeway, the tonnage of the equilibrium point of an ordinary highway is generally slightly lower in Table 5. The more the vehicle load is, the more the tonnage of the balance section is reduced. Among the six types of goods vehicles, the tonnage of the balance point was reduced by $21 \%$. It shows that due to the problem of highway toll, the total weight of category 6 vehicles on ordinary highway is the optimal state at 29.9 tons, but affected by highway toll, the load of 37.9 tons is the optimal value of category 6 vehicles.

For second-class highways, the largest traffic volume is category 6 goods vehicles, followed by category 1, accounting for $54.82 \%$ and $26.22 \%$ respectively. In the total load, category 6 trucks are the highest, followed by category 4 and category 2 goods vehicles. As can be seen from the average haul distance index, the average haul distance of category 6 goods vehicles is the longest, reaching $123.07 \mathrm{~km}$. Secondly, the average haul distance of three types of goods vehicles reached $101.37 \mathrm{~km}$ (Table 6).

3.3. Rate Analysis. The traffic flow and toll ratio of various trucks in the whole road network in Table 7, of which the toll ratio of category 6 vehicles is the highest, accounting for 


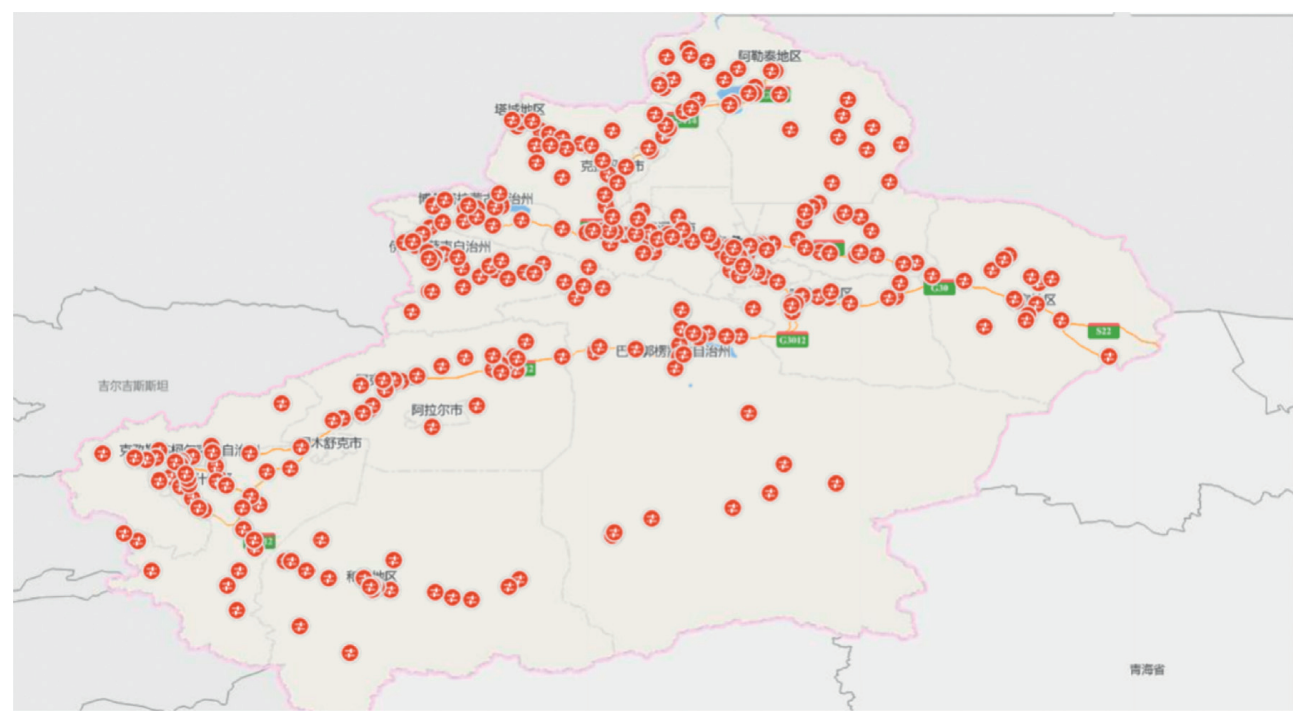

Figure 1: Toll station distribution in Xinjiang.

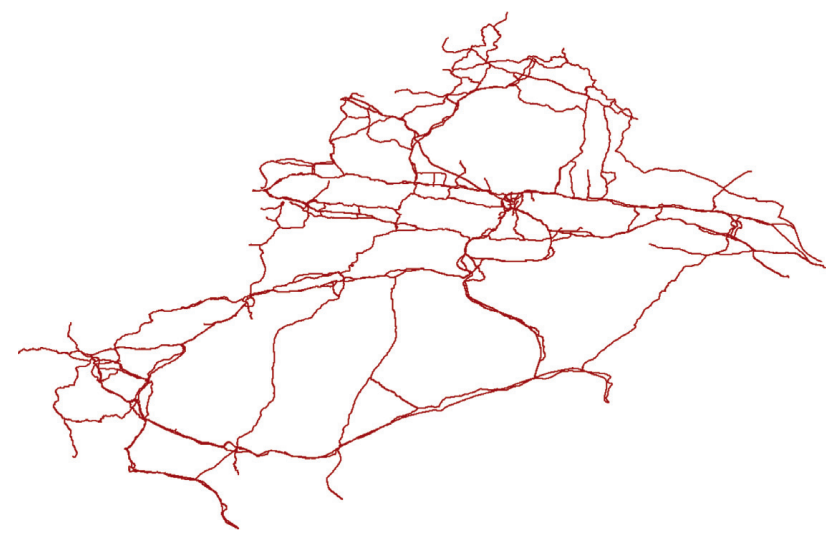

Figure 2: Distribution map of the freeway and first-class highway network in Xinjiang.

TABle 1: New standard goods vehicle classification in JT/T4892019.

\begin{tabular}{lc}
\hline Classification & Rules of classification \\
\hline Category 1 & 2 axles, vehicle length less than \\
& $6000 \mathrm{~mm}$, and maximum allowable \\
total mass less than $4500 \mathrm{~kg}$ \\
2 axles, vehicle length not less than \\
Category 2 & $6000 \mathrm{~mm}$, and maximum allowable \\
& total mass not less than $4500 \mathrm{~kg}$ \\
Category 3 & 3 axles \\
Category 4 & 4 axles \\
Category 5 & 5 axles \\
Category 6 & 6 axles \\
\hline
\end{tabular}

$88.09 \%$. It can be seen that category 6 vehicles with less than $70 \%$ of the traffic flow contributed nearly $90 \%$ of the tolls, and the total traffic flow of the remaining categories 1, 2, 3, 4, and 5 vehicles exceeded $30 \%$, only contributing about $10 \%$ of the tolls, indicating that category 6 heavy goods vehicles are the main force of highway tolls in Xinjiang. When adjusting
TABLe 2: New standard goods vehicle classification in JT/T4892003.

\begin{tabular}{lc}
\hline Classification & Rules of classification \\
\hline Category 1 & Less than $2000 \mathrm{~kg}$ \\
Category 2 & $2000 \mathrm{~kg}-5000 \mathrm{~kg}$ \\
Category 3 & $5000 \mathrm{~kg}-10000 \mathrm{~kg}$ \\
Category 4 & $10000 \mathrm{~kg}-15000 \mathrm{~kg}$ \\
Category 5 & More than $15000 \mathrm{~kg}, 40$ foot container \\
\hline
\end{tabular}

the charging rate policy, the impact of the rate on Category 6 goods vehicles should be considered mainly.

In China's previous toll road model classification standard, goods vehicles were divided into 5 types according to load mass, but now the model classification standard of JT/ T489-2019 is 6 types of goods vehicles, so it is necessary to realize the conversion from goods vehicle weight charging to model charging. According to the previous charging standard, the new rate standard determined according to the equivalent charging tonnage value is shown in Table 8 , in which the charging coefficient is the equivalent charging tonnage value, compared with the tonnage value of category 1 goods vehicles. The simple mapping relationship established by this scheme to realize the conversion of weight charging into vehicle charging can be used as a reference for the subsequent calculation of the adjustment and change of toll of the whole road network, but it cannot match the current toll standard, and there is still a certain gap with the actual situation of Expressway operation and cargo transportation in Xinjiang. In order to obtain the rate standard in line with the actual situation, it is also necessary to translate the static fee according to the current fee standard and analyze the dynamic traffic impact.

3.4. Traffic Demand Model. In this study, video traffic simulation software is used to build the analysis model. According to the GIS data of Xinjiang highway network, the network topology model of the freeway and first-class 
TABLE 3: Characteristics of various freight vehicles on Xinjiang freeway.

\begin{tabular}{lcccc}
\hline Classification & Volume (million vehicles/year) & Proportion (\%) & Average gross vehicle weight (ton) & Average haul distance $(\mathrm{km})$ \\
\hline Category 1 & 4.12 & 15.91 & 2.5 & 58.04 \\
Category 2 & 2.13 & 8.24 & 9.4 & 57.66 \\
Category 3 & 0.95 & 3.65 & 17.52 & 68.69 \\
Category 4 & 1.12 & 4.31 & 26.64 & 60.49 \\
Category 5 & 0.33 & 1.27 & 29.52 & 75.41 \\
Category 6 & 17.25 & 66.62 & 40.32 & 71.27 \\
Total & 25.89 & 100 & 20.98 & 65.26 \\
\hline
\end{tabular}

TABle 4: Distribution of light and heavy loads in freeway network.

\begin{tabular}{lccc}
\hline Classification & Balance point tonnage & Light load proportion (\%) & Heavy load proportion (\%) \\
\hline Category 1 & 4.11 & 100.00 & 0.00 \\
Category 2 & 8.92 & 62.04 & 37.96 \\
Category 3 & 16.33 & 53.24 & 46.76 \\
Category 4 & 22.98 & 49.21 & 50.79 \\
Category 5 & 28.68 & 48.88 & 51.12 \\
Category 6 & 37.94 & 29.31 & 70.69 \\
\hline
\end{tabular}

TABle 5: Distribution of light and heavy loads in the ordinary highway network.

\begin{tabular}{lccc}
\hline Classification & Balance point tonnage & Light load proportion (\%) & Heavy load proportion (\%) \\
\hline Category 1 & 3.59 & 93.79 & 6.21 \\
Category 2 & 8.29 & 62.74 & 37.26 \\
Category 3 & 15.14 & 42.08 & 57.92 \\
Category 4 & 19.69 & 41.39 & 58.61 \\
Category 5 & 21.9 & 56.61 & 43.39 \\
Category 6 & 29.86 & 37.85 & 62.15 \\
\hline
\end{tabular}

Table 6: Analysis on the proportion of goods vehicle traffic volume of each type (axle) of the second-class highway.

\begin{tabular}{lcccccc}
\hline Classification & $\begin{array}{c}\text { Volume } \\
(\text { million})\end{array}$ & $\begin{array}{c}\text { Proportion } \\
(\%)\end{array}$ & $\begin{array}{c}\text { Total weight (million } \\
\text { Tons) }\end{array}$ & $\begin{array}{c}\text { Miles (million } \\
\mathrm{km})\end{array}$ & $\begin{array}{c}\text { Average gross vehicle } \\
(\text { tons })\end{array}$ & $\begin{array}{c}\text { Average haul distance } \\
(\mathrm{km})\end{array}$ \\
\hline Category 1 & 1.16 & 26.22 & 2.83 & 93.48 & 2.43 & 80.44 \\
Category 2 & 0.46 & 10.29 & 4.31 & 39.63 & 9.45 & 86.92 \\
Category 3 & 0.15 & 3.32 & 2.96 & 14.93 & 20.12 & 101.37 \\
Category 4 & 0.20 & 4.56 & 5.37 & 18.85 & 26.58 & 93.33 \\
Category 5 & 0.03 & 0.79 & 0.93 & 3.35 & 26.76 & 96.1 \\
Category 6 & 2.43 & 54.82 & 90.67 & 469.01 & 37.32 & 123.07 \\
Total & 4.43 & 100 & 107.08 & 122.67 & 581.24 \\
\hline
\end{tabular}

TABLE 7: The proportion of traffic and tolls of all kinds of goods vehicles in the whole road network.

\begin{tabular}{lcc}
\hline Classification & Charge (million yuan) & Proportion $(\%)$ \\
\hline Category 1 & 68.7695 & 2.24 \\
Category 2 & 76.7629 & 2.50 \\
Category 3 & 72.9316 & 2.38 \\
Category 4 & 101.8359 & 3.32 \\
Category 5 & 44.5964 & 1.46 \\
Category 6 & 2699.912 & 88.09 \\
Total & 3064.808 & 100.00 \\
\hline
\end{tabular}

highway covering the whole Xinjiang in 2018, including 211 toll stations, is built in Figure 3. A total of 86 traffic zones are divided, including 16 external zones and 70 internal zones, as shown in Figure 3.

The traffic analysis model based on generalized cost is a common model to analyze the distribution and transfer of traffic volume in highway and urban road network. By calculating the generalized cost of vehicles in the road network and combined with the traffic volume charge transfer model, the travel path choice of traffic volume and the distribution of traffic volume in different sections of the 
TABLE 8: Calculation fee coefficient and rate standard of freeway goods vehicle model mapping.

\begin{tabular}{lccc}
\hline Classification & Rate standard of the freeway and first-class highway & Equivalent to weight charge tonnage & Charge coefficient \\
\hline Category 1 & 0.35 & 5 & 1 \\
Category 2 & 0.525 & 7.5 & 1.5 \\
Category 3 & 0.7 & 19 & 2 \\
Category 4 & 1.26 & 22 & 3.6 \\
Category 5 & 1.47 & 22 & 4.2 \\
Category 6 & 1.75 & 22 \\
\hline
\end{tabular}

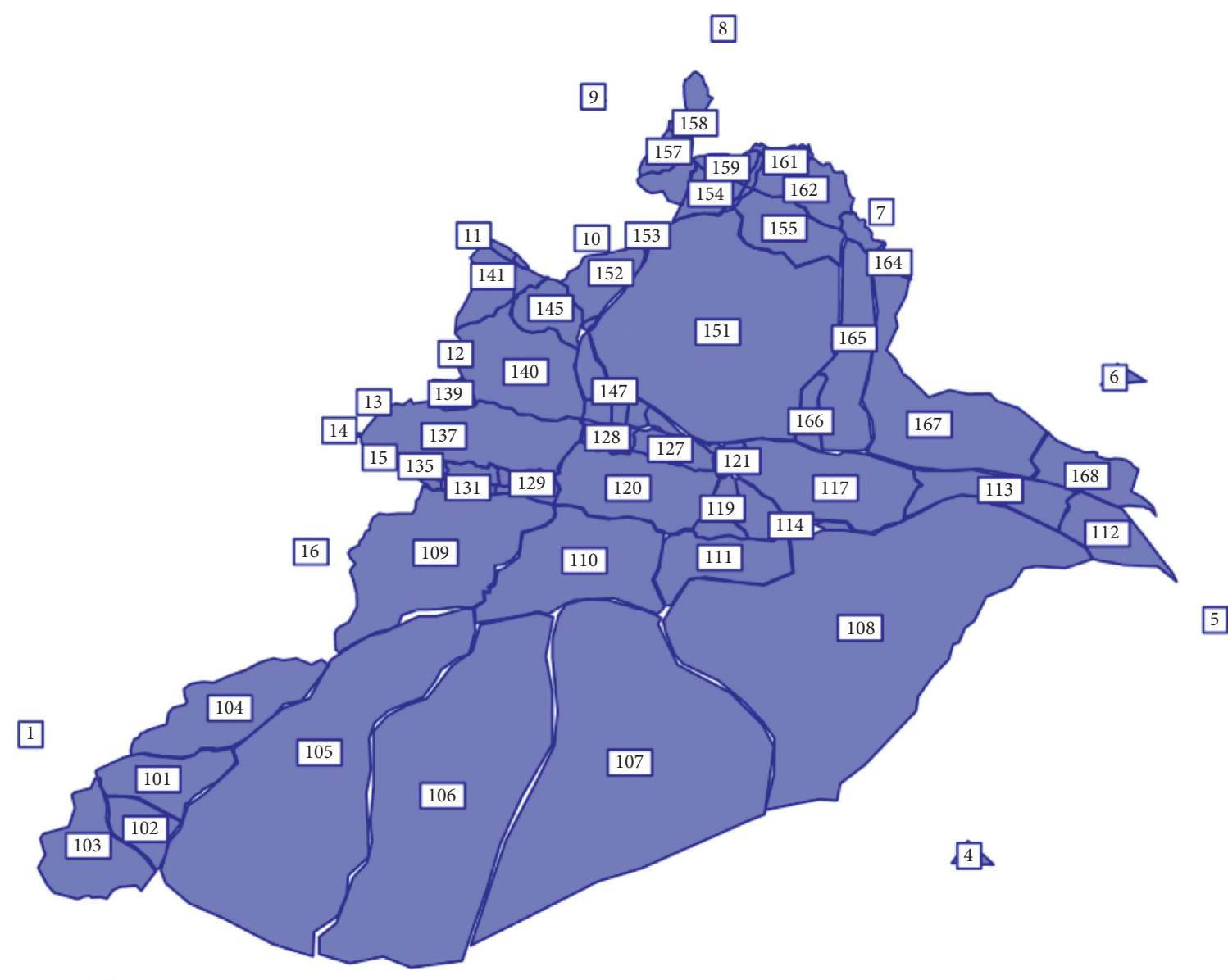

2.

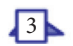

FIGURE 3: Highway network district division of Xinjiang.

road network under the condition of road charge can be calculated. In this study, the GDP method is used to calculate the conversion between time and cost. The GDP method is shown in the following equation:

$$
V O T=\frac{G D P}{(P \cdot T)}
$$

In equation (1), GDP is the gross national product (yuan). The $P$ represents the average annual employment (person). The $t$ represents the average personal working hours (hours). It is calculated that the per capita time value in Xinjiang is about 16.95 yuan/hour. For the impedance function of the road section, there are two parts, one is the highway charge, and the other is the cost of converting the motor vehicle travel time through the time value function. The sum of the two can be used. The generalized cost calculation and comparison can be carried out for trucks of different types and different loading conditions. Divide, distinguish the sensitivity of goods vehicle road toll under different truck types and different loading conditions, and form a generalized cost model of time and cost in a broad sense, so as to calculate the vehicle traffic path selection and traffic volume distribution under different toll rates. 
Through the TFlowFuzzy module in Visum, combined with the detailed traffic volume data of 211 toll stations of Xinjiang freeway and first-class Highway in 2018, the Highway Traffic Origin-Destination (OD) matrix of Xinjiang in 2018 is deduced. The accuracy of the distribution results of the inferred OD matrix is verified by the traffic volume of the whole network and freeway network so as to analyze the freight train rate scheme under the condition of dynamic influence. The model is divided into 20 traffic systems according to different types and loads of goods vehicles. The OD extrapolation results are highly matched with the observed values, and the accuracy is within $7.8 \%$. The inspection results of category 1-4 and category 6-3 of two transportation systems with large weight are shown in Figure 4.

\section{Result and Discussion}

According to the actual traffic volume of the road network in Xinjiang, the static and translational charging rate standard is adopted to calculate the comparison results between the charging and weight charging of the whole road network in Xinjiang in 2018, as shown in Table 4.

It can be seen intuitively from Table 9 that except that the total charge of category 1 goods vehicles has increased to a certain extent, the total charge of other types of goods vehicles has decreased to varying degrees, with the highest increase of $16.08 \%$ for category 1 goods vehicles, and the total charge of other types of goods vehicles has decreased. Compared with the weight charging scheme, the total charge of Category 3 goods vehicles has decreased the most, reaching 25.92\%. Obviously, this result is not in line with our original intention to adjust the rate. It does not reach the operating income of weight charging, with a difference of $9.81 \%$, but it cannot exceed $10 \%$ of the original weight charging in the process of adjustment. Therefore, the rate of this scheme should be dynamically adjusted to a certain extent.

The dynamic adjustment scheme is based on the above static fee translation scheme on the basis of considering the factors of the traffic volume transfer. Based on the generalized cost principle, the analysis model of toll roads in Xinjiang in 2018 is built to optimize the static fee and translation rate. The optimal rate scheme is obtained on the premise of meeting the constraints. The requirements of this optimization will not increase the overall burden of the whole society and reduce the goods vehicles toll to the greatest extent in the transition from weight charging to vehicle charging. The specific requirements and constraints are as follows. Firstly, the goods vehicles toll of the whole road network calculated based on the traffic volume in 2018 shall not be greater than the toll charged by weight under the same traffic volume. Secondly, the toll of each goods vehicles model shall not be greater than the weight charge corresponding to the upper limit of legal loading. The amount of goods vehicles toll on freeway shall be as close as possible to the amount of toll under the condition of weight charging. The optimization idea is to comprehensively consider the current charging standard, goods vehicles preferential reduction and exemption, and other factors. According to each type of vehicle (number of axles), the charging standard is equal to the average charging standard of the same type according to the original weight calculation mode. Finally, under the condition that the goods vehicles traffic volume and average haul distance of the road network remain unchanged, the total toll amount of the road network will be consistent. According to different rate adjustment coefficients, the rate test is combined into the following five schemes. These schemes are increased by $10 \%, 11 \%, 12 \%, 13 \%$, and $14 \%$, respectively, compared with the static translation rate. After the rate adjustment, according to the relevant national regulations and standards, and considering that ETC owners enjoy a $95 \%$ discount on the toll and deduct $9 \%$ of the value-added tax, the dynamically adjusted toll calculation of the above five schemes is shown in Table 10.

As can be seen from Table 10, according to the topology analysis, the original weight toll limit is 3309.15 million yuan, and the translation toll limit according to the charge converted based on volume charge statistics is 2984.59 million yuan. In the case of dynamic adjustment of $10 \%$ to $14 \%$ of the rate for Category 6 goods vehicles, the maximum toll amount is 3402.46 million yuan, exceeding the original weight charge amount. However, after the $95 \%$ discount and VAT deduction, the toll amount of scheme 5 with the rate rising by $14 \%$ is 3096.24 million yuan, which is close to the toll amount. Considering the economic route sensitivity of goods vehicles, some vehicles give up the freeway route and choose the low-grade highway communication with free or lower toll amount, resulting in the natural reduction demand of traffic volume lost by the original weight toll amount. At the same time, it should also take into account the gradual implementation of ETC, wider coverage, and the gradual transformation of the freeway into the operational freeway. Among them, the travel cost pressure of travelers cannot be increased. Scheme 4 is recommended; that is, the rate increases by $13 \%$.

It shows the comparison between the weight charging standard of category 1-6 goods vehicles and the new charging standard of the recommended scheme in Table 11. When the weight tonnage is equal to the charging mileage, the new charging standard of the recommended scheme for category 1-6 goods vehicles is increased by $1 \%$ compared with the weight charging amount. It reached 884 yuan per 100 kilometers. Under the new charging standard, the toll of category 6 goods vehicles accounted for $91.6 \%$, an increase of $0.1 \%$ compared with $91.7 \%$ of the previous weight charging. Under the condition of driving 100 kilometers, the charging amount of class 1 , class 5 , and class 6 goods vehicles increased by $33 \%, 2 \%$, and $6 \%$, respectively, the charging amount of class 2 and class 3 goods vehicles decreased by $16 \%$ and $7 \%$, and the charging amount of class 4 goods vehicles remained unchanged. Under the new model charging method of the recommended scheme, the overall charging amount is basically consistent compared with the weight charging state, which can meet the requirement of not increasing the overall traffic cost burden of the society. 


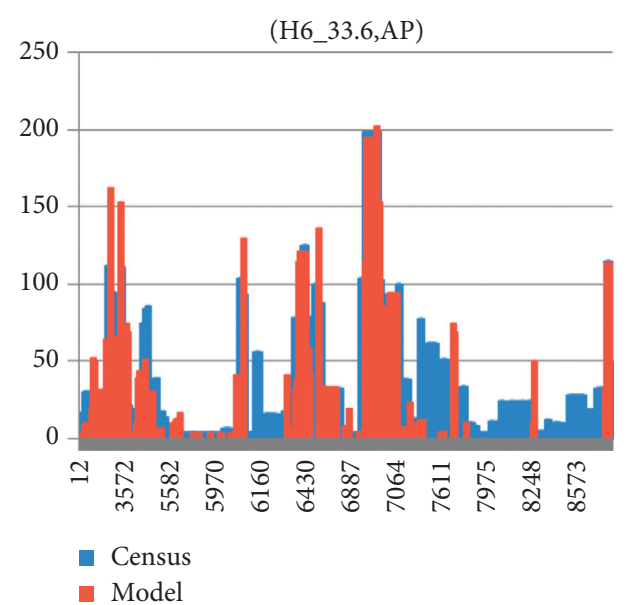

(a)

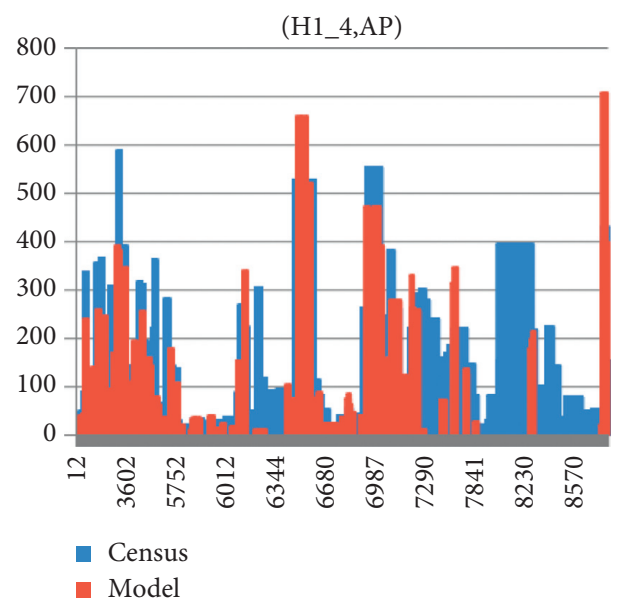

(b)

FIGURE 4: Model accuracy check chart of a different system. (a represents categories 1-4, system and b represents categories 6-3. The abscissa in the figure is the section number and the ordinate is the volume. The blue bar represents the survey data, and the red bar represents the data predicted by the model.)

TABle 9: Weight charge and static translation scheme comparison.

\begin{tabular}{lcccc}
\hline Classification & $\begin{array}{c}\text { Real total weight charge (million } \\
\text { yuan) }\end{array}$ & $\begin{array}{c}\text { Prediction total vehicle charges (million } \\
\text { yuan) }\end{array}$ & $\begin{array}{c}\text { Changes (million } \\
\text { yuan) }\end{array}$ & $\begin{array}{c}\text { Rate of change } \\
\text { Category 1 }\end{array}$ \\
Category 2 & 42.41 & 49.23 & 6.82 & $16.08 \%$ \\
Category 3 & 62.93 & 57.70 & -5.24 & $-8.32 \%$ \\
Category 4 & 58.64 & 43.44 & -15.20 & $-25.92 \%$ \\
Category 5 & 76.78 & 67.44 & -9.35 & $-12.17 \%$ \\
Category 6 & 34.42 & 32.88 & -1.54 & $-4.48 \%$ \\
Total & 3033.97 & 2733.91 & -300.06 & $-9.89 \%$ \\
\hline
\end{tabular}

TABLE 10: Toll calculation table after dynamic adjustment of different rates.

\begin{tabular}{lccc}
\hline Scheme & Toll (million Yuan) & After 15\% discount (million Yuan) & After VAT (million Yuan) \\
\hline Up 10\% & 3283.08 & 3118.93 & 2987.60 \\
Up 11\% & 3312.92 & 3147.27 & 3014.76 \\
Up 12\% & 3342.78 & 3175.64 & 3041.93 \\
Up 13\% & 3372.62 & 3203.99 & 3069.08 \\
Up 14\% & 3402.46 & 3232.34 & 3096.24 \\
Original weight & 3309.15 & & \\
Fee translation & 2984.59 & & \\
\hline
\end{tabular}

TABLE 11: Comparison of new and old freight charges.

\begin{tabular}{lcccc}
\hline Classification & $\begin{array}{c}\text { Weight charging } \\
\text { standard (yuan/ton } \\
\mathrm{km})\end{array}$ & $\begin{array}{c}\text { Charging standard of } \\
\text { recommended scheme (yuan/ } \\
\mathrm{km})\end{array}$ & $\begin{array}{c}\text { Weight charge } \\
\text { amount (yuan/ } \\
100 \mathrm{~km})\end{array}$ & $\begin{array}{c}\text { Recommended scheme } \\
\text { charge (yuan/100 km) }\end{array}$ \\
\hline Category 1 & 0.07 & 0.40 & 30 & 40 \\
Change \\
Category 2 & 0.07 & 0.72 & 86 & 72 \\
Category 3 & 0.07 & 1.31 & 141 & 131 \\
Category 5 & 0.07 & 1.80 & 180 & -0.16 \\
Category 6 & 0.07 & 2.08 & 204 & -0.07 \\
Total & 0.07 & 2.53 & 238 & 0.00 \\
\hline
\end{tabular}




\section{Conclusion}

This paper studies the rate optimization scheme of the regional toll road network by establishing the toll road network model in the Xinjiang Autonomous Region. By analyzing the dynamic impact of the change of rate standard, the recommended best rate adjustment coefficient scheme is obtained, and the volume cost characteristics after coefficient adjustment are calculated and verified. The results show that under the new recommended rate standard, the toll of category 1, 5 , and 6 goods vehicles increases by $33 \%$, $2 \%$, and $6 \%$, respectively, compared with the previous weight charging standard. 2. The tolls of Category 3 goods vehicles decreased by $16 \%$ and $7 \%$, respectively. The overall toll remains basically unchanged, and it can basically be realized without increasing the overall traffic cost burden of the society.

\section{Data Availability}

The data used to support the findings of this study are available from the corresponding author upon request.

\section{Ethical Approval}

All methods were carried out in accordance with relevant guidelines and regulations. All experimental protocols were approved by a named institutional and/or licensing committee.

\section{Consent}

Informed consent was obtained from all subjects and/or their legal guardian(s).

\section{Conflicts of Interest}

The authors declare that there are no conflicts of interest regarding the publication of this paper.

\section{Authors' Contributions}

Hua Zhao and Zhihong Li conceptualized and designed the study; Hua Zhao, Zifeng Peng, and Weiting Yao collected data; Hua Zhao and Zhihong Li took part in analysis and interpretation of results; Hua Zhao, Zifeng Peng, and Zhihong Li prepared the draft manuscript. All authors reviewed the results and approved the final version of the manuscript.

\section{Acknowledgments}

This paper was supported by the National Social Science Foundation (21FGLB014) and the Platform project of Jiangxi Provincial Science and Technology Department (20171BCD40017).

\section{References}

[1] X. Chen, H. Chen, Y. Yang et al., "Traffic flow prediction by an ensemble framework with data denoising and deep learning model," Physica A: Statistical Mechanics and Its Applications, vol. 565, Article ID 125574, 2021.

[2] Y. Yang, Z. Yuan, J. Chen, and M. Guo, "Assessment of osculating value method based on entropy weight to transportation energy conservation and emission reduction," Environmental Engineering and Management Journal, vol. 16, no. 10, pp. 2413-2423, 2017.

[3] X. Chen, J. Lu, J. Zhao, Z. Qu, Y. Yang, and J. Xian, “Traffic flow prediction at varied time scales via ensemble empirical mode decomposition and artificial neural network," Sustainability, vol. 12, no. 9, p. 3678, 2020.

[4] Z. Pu, Z. Li, R. Ke, X. Hua, and Y. Wang, "Evaluating the nonlinear correlation between vertical curve features and crash frequency on highways using random forests," Journal of Transportation Engineering, Part A: Systems, vol. 146, no. 10, Article ID 04020115, 2020.

[5] Z. Li, Y. Dong, Y. Wen, H. Xu, and J. Wu, “A deep pedestrian tracking SSD-based model in the sudden emergency or violent environment," Journal of Advanced Transportation, vol. 2021, pp. 1-13, Article ID 2085876, 2021.

[6] A. Abulibdeh, "Implementing congestion pricing policies in a MENA Region City: analysis of the impact on travel behaviour and equity," Cities, vol. 74, pp. 196-207, 2018.

[7] S. Agarwal and K. M. Koo, "Impact of electronic road pricing (ERP) changes on transport modal choice," Regional Science and Urban Economics, vol. 60, pp. 1-11, 2016.

[8] L. Xie and P. Olszewski, "Modelling the effects of road pricing on traffic using ERP traffic data," Transportation Research Part A: Policy and Practice, vol. 45, no. 6, pp. 512-522, 2011.

[9] P. T. Martin, D. Lahon, and A. Stevanovic, "Review of the effectiveness of the high occupancy vehicle (HOV) lanes extension," University of Utah, vol. 10, pp. 1-40, 2005.

[10] X. Yu, "Analysis on the impact of differentiated charging of freight cars in different periods on Chengdu Mianyang Leshan economic corridor. China Association for science and technology, Ministry of transport of the people's Republic of China, Chinese Academy of engineering," in Proceedings of the 2019 World Transportation Conference (Part I). China Association for science and technology, Ministry of transport of the people's Republic of China, Chinese Academy of Engineering, pp. 1015-1022, China highway society, Xi'an, China, June 2019.

[11] W. Mao, L. Zhu, J. Wang, k. Xia, and X. Fu, "Impact assessment of differentiated charging of Ring Freeway Based on four stage model," Transportation technology and economy, vol. 20, no. 4, pp. 72-75, 2018.

[12] M. Li, Research on Multi-Dimensional Differential Charging Decision-Making Method of Freeway Goods Vehicles under BOT Operation Mode, Chang'an University, Xi'an, China, 2019.

[13] Z. Yang and D. Zhao, "Formulation method of optimal toll standard of Changping Freeway," Journal of Transportation Engineering, vol. 3, no. 1, pp. 57-61, 2003.

[14] C. Li, "Research on traffic demand management strategy of competitive freeway network based on game analysis," Highways, vol. 58, no. 12, pp. 142-145, 2013.

[15] P. Yao and S. Wang, "Countermeasure analysis of optimizing Freeway pricing -- from the perspective of PPP project decision-making characteristics," Price theory and practice, vol. 2011, no. 4, pp. 81-82, 2011.

[16] J. Xie, X. Jin, Y. Peng, Z. Tan, and S. Xie, "Study on Optimization of freeway toll rate," Price theory and practice, vol. 1018, no. 3, pp. 59-62, 2018. 
[17] S. Taothon, P. Jiwattanakulpaisarn, and K. Kanitpong, An Empirical Analysis of Success and Failure Factors for PublicPrivate Partnerships in Toll Road Investments, pp. 11-3586, Transportation Research Board, Washington, DC, 2012.

[18] J. L. Steed and C. R. Bhat, Modeling Departure Time Choice for home-based Non-work Trips, pp. 1-53, Southwest Region University Transportation Center, Center for Transportation Research, University of Texas at Austin, Austin, Texas, 2000.

[19] L. Fu, Study on Optimization of Toll Rate of Xinyu Fuling Freeway under Competitive Conditions, Chongqing Jiaotong University, Chongqing, China, 2015.

[20] F. Wang, Q. Wu, and H. Guo, "Toll road rate optimization method to deal with financial crisis," Highway transportation technology, vol. 34, no. 8, pp. 152-158, 2017.

[21] Z. Zhou, K. Zhang, W. Zhu, and Y. Wang, "Modeling lanechoice behavior to optimize pricing strategy for HOT lanes: a support vector regression approach," Journal of Transportation Engineering, vol. 145, no. 4, pp. 1-12, 2019.

[22] F. S. Koppelman and C. Bhat, A Self-Instructing Course in Mode Choice Modeling: Multinomial and Nested Logit Models, pp. 1-249, U.S Department of Transportation Federal Transit Administration, Washington, D.C., 2006.

[23] P. Brinckerhoff and T. T. Institute, A Guide of HOT Lane Development, pp. 1-106, U.S. Department of Transportation Federal Highway Administration, Washington, D.C., 2002.

[24] Z. Yuan, K. He, and Y. Yang, "A roadway safety sustainable approach: modeling for real-time traffic crash with limited data and its reliability verification," Journal of Advanced Transportation, vol. 2022, Article ID 1570521, 14 pages, 2022. 